\title{
Effect of Gamma Irradiation on the Sterility and Other Quality Parameters of Sterile Male Culex quinquefasciatus (Diptera: Culicidae)
}

\author{
Tri Ramadhani ${ }^{*}$, Upik Kesumawati Hadi $^{2}$, Susi Soviana ${ }^{2}$, Z Irawati $^{3}$ \\ ${ }^{1}$ Banjarnegara of Health Research and Development, Banjarnegara, Central Java 53415, Indonesia \\ ${ }^{2}$ Entomology Laboratory, Department of Parasitology and Medical Entomology, Faculty of Veterinary Medicin -IPB \\ Darmaga, Bogor 16680, Indonesia \\ ${ }^{3}$ Center for Isotope and Radiation Application (CIRA)-National Nuclear Energy Agency (BATAN), North Jakarta 12440, \\ Indonesia \\ *Corresponding author. Email: 3rdhani@gmail.com
}

\begin{abstract}
Culex quinquefasciatus is a vector of lymphatic filariasis caused by Whuchereria brancofti in Indonesia. Even though sterile insect technique has not been introduced to Indonesia yet, a strong emphasis is being placed on developing effective measures to suppress this vector and to prevent its transmission to another area. The sterile insect technique was widely used in integrated vector management against infectious mosquitoes and, in this paper, quality parameters of irradiated Culex quinquefasciatus were evaluated for possible use of sterile insect technique within the management of this vector. Six sterilizing doses 0 (control) 60; 65; 70; 75 and $80 \mathrm{~Gy}$ of gamma radiation were tested against pupae full-grown male of Culex quinquefasciatus. The results showed that fecundity of non-irradiation females mating with irradiated males was decreased by increasing irradiation dose. The decrease in egg hatchability and increase in sterility induced by gamma radiation were found to be positively correlated with the dose level. While adult emergence and egg hatch decreased with increasing dose, no significant differences in adult emergence, age, longevity and female fecundity were found among doses.
\end{abstract}

Keywords: gamma irradiation, sterile insect technique, Culex quinquefasciatus, sterility

\section{INTRODUCTION}

Culex quinquefasciatus is the main vector of lymphatic filariasis in the City of Pekalongan [1,2]. Various vector control measures have been implemented to reduce the population. The continuous use of insecticides in mosquito control, has resulted in the emergence of resistant mosquito populations and environmental pollution. To overcome this problem, alternative control efforts need to be developed, among others, with Sterile Insect Technique (SIT). This method began to be developed because it is environmentally friendly, it has specific targets and does not cause resistance effects on insects [3]. In Indonesia, the SIT approach to reduce the $C x$. quinquefasciatus mosquito population has never been carried out, so far it is still in the form of a preliminary test to support the successful application of SIT in nature [4].

The principle of SIT is controlling insects (mosquitoes) by releasing sterile mosquitoes into nature with the aim that a mating occurs between sterile mosquitoes and fertile mosquitoes in nature. Sterile mosquito release can gradually reduce mosquito populations in nature [5]. The insect sterilization process can be carried out using gamma irradiation from Co-60 radioisotopes which have a long half-life, and relatively high energy [6]. Controlling mosquito populations using the SIT approach is not always successful, because it is highly dependent on the quality of infertile males in competing with fertile males in the wild [7]. Declining quality and competitiveness of infertile males can occur due to gamma ray irradiation treatment, so it is necessary to release more infertile males (inundation) at the release site [8]. Therefore, the production of infertile males in large quantities must be done in the most easy and effective way.

According to Knipling [8] exposure to ionizing irradiation against insects causes sterilization through dominant lethal mutations in genetic material. The effect of irradiation results in the death of sperm or egg after being produced, can genetically cause sperm and egg cells to become infertile, ultimately can not produce offspring [9].

The process of gamma irradiation will result in fertility insects, this is due to among others the occurrence of sperm in activation, dominant lethal mutations, aspermia and the inability to mate from male or female insects [10]. Rodriguez (1977) reported a 50 Gy gamma irradiation in 


\subsubsection{Emergency rate}

aegypti results in a decrease in productivity or heredity [11]. Helinski and Knols (2009) reported that gamma irradiation can reduce sperm quantity and the mating competitiveness of Anopheles arabiensis mosquitoes as malaria vectors [12]. Bellini et al (2013) reported semifield test Ae. albopictus gamma irradiated at a dose of 30$60 \mathrm{~Gy}$, shows a decrease in marital competitiveness at a greater gamma irradiation dose [13].

\subsection{Materials and Methods}

The study design used was a completely randomized design (CRD) with six treatments and four replications. The insect population of the test was the Culex spp mosquito originated from collecting eggs and larvae in Pekalongan City, Indonesia The larvae of $C x$. quinquefasciatus obtained from the field, then maintained to become pupae in entomology laboratory of the Banjarnegara of Health Research and Development. For transportation, pupae are put in $100 \mathrm{ml}$ plastic cups with a little water $(+5 \mathrm{ml})$. The number of pupae per plastic cup is 50 pupas. Then the plastic cups are arranged in a box equipped with banana fronds inside to keep the moisture stable. During the trip, humidity measurements were taken using a digital hydrometer. The research sample is all pupae male of $C x$. quinquefasciatus that are maintained in the laboratory.

This research was conducted at the Entomology Laboratory in the Banjarnegara of Health Research and Development with room conditions maintained at a temperature of $25-28^{\circ} \mathrm{C}$ and humidity of $80 \%$. Gamma irradiation of $C x$. quinquefasciatus pupae was conducted at the Central of Isotopes and Radiation Application (PAIR) of the National Nuclear Energy Agency (BATAN) in South Jakarta. Observations were done at the entomology laboratory in the Banjarnegara of Health Research and Development.

\subsubsection{Irradiation with Gamma Cell 220}

Male pupae before being irradiated with gamma ray Co-60 were inserted into a plastic tube measuring the bottom diameter $4.5 \mathrm{~cm}$ the top $6.5 \mathrm{~cm}$ high $6.5 \mathrm{~cm}$ and $175 \mathrm{ml}$ volume with a density of 50 head/tube. The irradiated pupae is a pupae aged $>15$ hours. Irradiation was carried out using a Gamma Cell 220 irradiator at a dose of $60 \mathrm{~Gy}, 65 \mathrm{~Gy}, 70 \mathrm{~Gy}, 75 \mathrm{~Gy}$ and $80 \mathrm{~Gy}$, with a dose rate between $114.29-116.13 \mathrm{~Gy} /$ hour. As control is male pupae of $C x$. quinquefasciatus non-irradiated which has been prepared in the entomology laboratory of the Banjarnegara of Health Research and Development.
The irradiated male pupae $(\mathrm{n}=50)$ were put in a $12 \mathrm{~cm}$ x $12 \mathrm{~cm}$ x $12 \mathrm{~cm}$ mosquito cage and kept until they became adult mosquitoes. As control is male pupae that is not irradiated. The emerging male mosquitoes were counted and put in a mosquito cage of $30 \mathrm{~cm} \times 30 \mathrm{~cm} \times 30$ $\mathrm{cm}$ to be tested for the length of its life (age). The treatment was carried out at all irradiation doses with four replications. Percentage of infertile adult is obtained from the calculation of the number of infertile adlt mosquitoes, both living and dead divided by the number of pupae multiplied by $100 \%$

\subsubsection{Longevity}

The irradiated male mosquito pupae $(\mathrm{n}=25)$ were placed in a $30 \mathrm{~cm} \times 30 \mathrm{~cm} \times 30 \mathrm{~cm}$ cage and were given a $10 \%$ sugar solution. Control is male mosquitoes that are un irradiated. The longevity was the number of days it takes for an irradiated male mosquito to develop from the larval stage until it dies. Longevity was determined by counting the number of dead mosquitoes and removing them from the maintenance cage at 24 hours intervals. The treatment was carried out at all irradiation doses with four replications

\subsubsection{Fecundity, sterility and hatchability}

Irradiate male mosquitoes of $C x$. quinquefasciatus $(\mathrm{n}=25)$ mated with non-irradiated female mosquitoes $(\mathrm{n}=$ 25) in a cube cage of $30 \mathrm{~cm} \times 30 \mathrm{~cm} \times 30 \mathrm{~cm}$. Control using non-irradiate male mosquitoes of $C x$. quinquefasciatus $(\mathrm{n}=25)$ mated with non-irradiated female mosquitoes $(n=25)$. Three days after of mating, male mosquitoes were removed from the cage using an aspirator. Female mosquitoes were fed blood on-marmot until they are full of blood $( \pm 1$ hour), then individually transferred into a transparent plastic vial tube for the oviposition process [14]. The treatment was carried out at all irradiation doses by repeating four times.

Observation of the number of eggs, eggs hatched, and did not hatch was calculated manually using a stereo microscope with magnification $4 \mathrm{x}$ for five days after oviposition. Eggs with open operculum are hatched eggs, whereas non-hatched eggs are characterized by unopened egg operculum [15]. Sterility is calculated by comparing the number of eggs that do not hatch with the total number of eggs. 
showed the percentage of adult emergence of non-

\subsubsection{Data analysis}

Data on age, emergency rate, fecundity, hatchability and sterility were grouped to obtain mean values, standard deviations and variants with the help of SPSS 16 software. One way analysis of variance (ANOVA) was used to evaluate the effect of gamma irradiation dose on parameters tested. Duncan's post hoc test was used for further analysis of comparisons between averages.

\subsection{Our Contribution}

This paper provides data in the form of the gamma irradiation effect several dose variations on the quality of sterile male of culex quinquefasciatus determined by adult emergence, longevity, survival, fertility, fecundity, hatchability and sterility.

\subsection{Paper Structure}

The structure of the research paper is organized as followes. Section 1 is an introduction that includes the use of gamma irradiation in the suppression of the Culex quinquefasciatus population, the support of other similar research results, and includes the workings of each variable that determines the quality of sterile male mosquitoes Culex quinquefasciatus. Section 2 contains the results of the research presented in graphical and tabular form and statistical analysis by comparing the results of other similar studies of others. Section 3 concludes the paper and provides suggestions for further research.

\section{RESULTS AND DISCUSSION}

\subsection{Adult Emergence}

Percentage values of the appearance of adult Cx.quinquefasciatus are presented in Table 1. The results irradiated pupae was higher than irradiated pupae. Percentage of adult $C x$. quinquefasciatus from irradiated pupae ranged from $89.5 \%$ to $91.3 \%$ while in controls $96.6 \%$ the percentage of emergence into adult mosquitoes at all gamma irradiation doses showed no significant differences $(p>0.05)$.

The percentage of adult emergence was one of the important parameters in the gamma irradiation process at the pupae stage. That matter as evidence that gamma irradiation does not inhibit the metamorphosis of the Cx.quinquefasciatus. The irradiated pupae must be able to develop into an adult mosquito within 1-2 days. The results showed gamma irradiation at a dose of 60-80 Gy did not affect the value of the appearance of adult $C x$. quinquefasciatus. In other words, pupae from gamma irradiation can develop into adult $C x$. quinquefasciatus. The selection of pupae age more than 15 hours can reduce death and pupae failure into adulthood. The pupae was the stage of development where the young organs transform into adult organs. This shows that gamma irradiation did not inhibit growth from pupae to adult (table 1). This result was in line with the research of Abdel-Malek who reported that gamma irradiation at the pupal stage had no effect on the adult emergence value of An. Pharoensi [16]. Similar results were reported in the An.arabiensis and Ae. Aegypti $[17,18]$.

\subsection{Longevity}

Table 2 shows the average age of male $C x$. quinquefasciatus at various doses of irradiation. Male $C x$. quinquefasciatus with a 70 Gy irradiation dose has the shortest longevity, while a 60 Gy irradiation dose produces the longest. The average age of irradiated mosquitoes is shorter when compared to controls. Statistical test results showed no significants difference in gamma irradiation dose with the age of male mosquitoes $C x$. quinquefasciatus $\mathrm{F}=0.793 ; \mathrm{p}>0.05$.

Table 1 The rate of $C x$. quinquefasciatus after gamma irradiation at the pupae stage

\begin{tabular}{|c|c|c|c|}
\hline Doses $(\mathbf{G y})$ & $\mathbf{N}$ & Replicate & Longevity (day) \\
\hline $0($ Control) & 25 & 4 & $26.93 \pm 1.73^{\mathrm{a}}$ \\
\hline 60 & 25 & 4 & $26.61 \pm 1.25^{\mathrm{a}}$ \\
\hline 65 & 25 & 4 & $25.63 \pm 1.16^{\mathrm{a}}$ \\
\hline 70 & 25 & 4 & $23.75 \pm 2.70^{\mathrm{a}}$ \\
\hline 75 & 25 & 4 & $24.74 \pm 2.58^{\mathrm{a}}$ \\
\hline 80 & 25 & 4 & $25.82 \pm 3.43^{\mathrm{a}}$ \\
\hline
\end{tabular}

The different superscripts in the same columns show significant difference $(\mathrm{p}<0.05)$ in ANOVA Duncan's post hoc test 
Table 2 Average longevity of male Culex quinquefasciatus after of gamma irradiation Co-60

\begin{tabular}{|c|c|c|c|}
\hline Doses (Gy) & $\mathbf{N}$ & Replicate & Emergency rate (\%) \\
\hline 0 (control) & 50 & 4 & $96,6 \pm 3,8^{\mathrm{a}}$ \\
\hline 60 & 50 & 4 & $91,3 \pm 2,3^{\mathrm{a}}$ \\
\hline 65 & 50 & 4 & $93,8 \pm 5,2^{\mathrm{a}}$ \\
\hline 70 & 50 & 4 & $94,5 \pm 5,0^{\mathrm{a}}$ \\
\hline 75 & 50 & 4 & $95,3 \pm 6,0^{\mathrm{a}}$ \\
\hline 80 & 50 & 4 & $89,5 \pm 2,3^{\mathrm{a}}$ \\
\hline
\end{tabular}

The different superscripts in the same columns show significant difference $(\mathrm{p}<0.05)$ in ANOVA Duncan's post hoc test

The effect of gamma irradiation on mosquito life did not show any real significance. Age of mosquitoes in this case is defined as the ability of $C x$. quinquefasciatus gamma irradiation to survive like mosquitoes in the field (wild type) [19]. Despite the age sterile male of $C x$. quinquefasciatus was not different from non-irradiated, but the results of the study showed that the age of irradiated mosquitoes tends to be shorter than that of control mosquitoes. Abdel-Malek et al. [16] reported that gamma irradiation at doses of 100-130 Gy reduced the age of An. Pharoensis. Sharma et al. [20] reported a decrease in the age of An. stephensi after gamma irradiation at doses of 80 and 120 Gy. Oliva et al. [21] also reported the effects of gamma irradiation on the age of Ae.albopictus in a semifield trial on Reunion Island, one of the French regions of the Indian Ocean]. The results showed that the age of gamma irradiated mosquitoes was lower than that of field mosquitoes. At high doses of gamma irradiation, somatic cell damage occurs which results in disruption of fitness and low mosquito life [22].

\subsection{Survival of Sterile Male Culex quinque- fasciatus}

Figure 1 shows the survival of male Cx.quinquefasciatus with various doses of irradiation. Death begins on the first day (age one day) except at a dose of 70 Gy irradiation (age two days), while death on control occurs only on day four (age four days). In general, the number of irradiated male of $C x$. quinquefasciatus tends to decrease faster or have a shorter life span compared to controls. The results showed that life rate of irradiated $C x$. quiquefasciatus tended to die more quickly than controls. Death of irradiated mosquitoes begins on the first day, only at a dose of 70 Gy death occurs after the third day, while control on the fifth day (figure 1). The effects of gamma irradiation will disrupt the mosquito's metabolic system resulting in more rapid death than nonirradiated mosquitoes, even if adequate food intake were given. Amin et al. reported on Culex pipiens $L$ with gamma irradiation doses of 40, 60, 80 Gy decreased carbohydrate, lipid and protein contents throughout the body after 24,48 and $72 \mathrm{hr}$ after the appearance of pupae

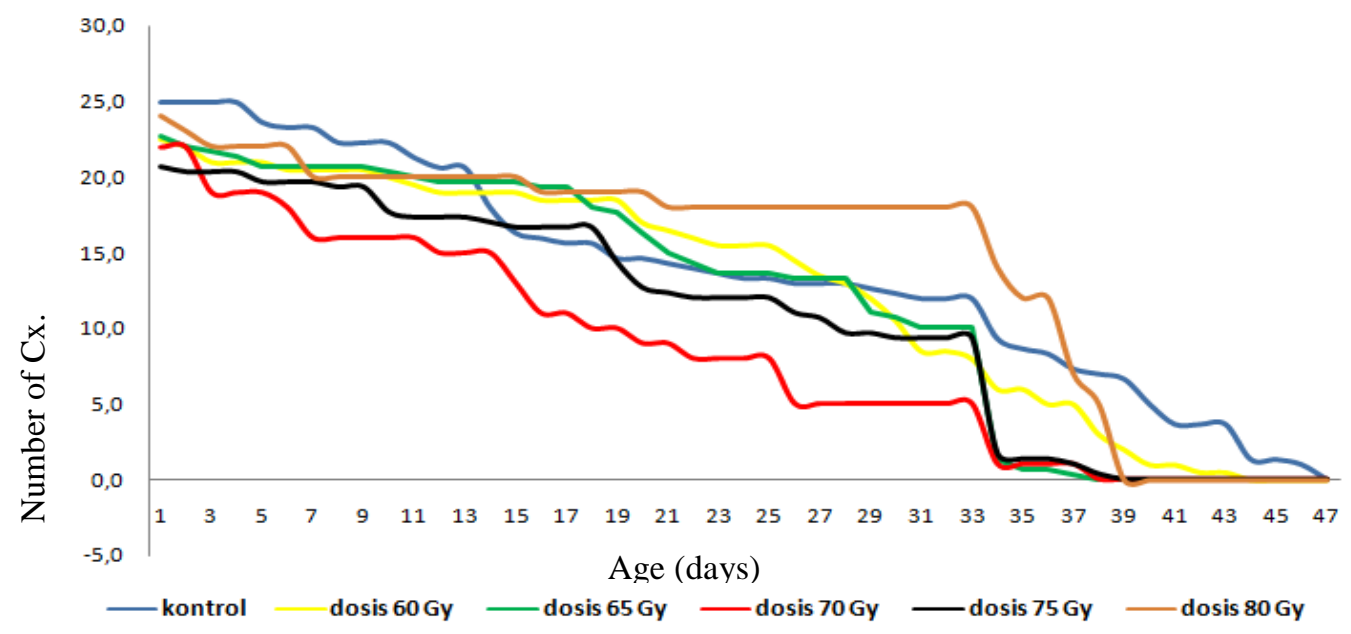

Figure 1 Survival of sterile male Culex quinquefasciatus with various doses irradiation 
Ramadhani et al. [2] reported that Ae.aegypti exposed [23]. There was a decrease in carbohydrate, pleated and protein content which causes irradiated mosquitoes to die faster than control mosquitoes.

\subsection{Fertility, Fecundity and Hatchability}

Fecundity and hatchability of Cx.quinquefasciatus eggs that successfully spawn from non-irradiated female mosquitoes mated with irradiated males and non-irradiated males as controls are presented in Table 3 .

The average percentage of female mosquitoes that successfully lay eggs by $40 \%$ in the control and $22 \%-43 \%$ in the treatment and statistically there was no difference $(\mathrm{F}$ $=2.201 ; \mathrm{p}=0.099)$. The highest average number of eggs produced per female mosquito $C x$. quinquefasciatus per oviposition was at the irradiation dose of 70 Gy $(120.7+$ 11.1) and the lowest was at the dose of 80 Gy $(96.4+$ 27.5). The observations showed no difference in the average number of eggs per female $C x$. quinquefasciatus at various irradiated doses with controls $(\mathrm{F}=0.907 ; \mathrm{p}=$ $0.498 ; \mathrm{p}>0.05$ ) (Table 3).

Egg hatchability is the percentage of the number of hatching eggs that hatch from the total number of eggs produced by female mosquitoes mated with sterile male mosquitoes or non-irradiated male mosquitoes. Egg hatchability of female mosquitoes mated with irradiated and control male mosquitoes is presented in Table 3 . Nonirradiated female mosquitoes mated to non-irradiated males have the highest average hatchability of $96.14 \%$, while those mated with irradiated males ranging from 1.3$4.8 \%$. There is a decrease in the level of hatchability of eggs, the higher the irradiation dose the lower the level of hatchability of the eggs. Statistical test results showed that there were significant differences in the level of hatchability between treatment and control $(\mathrm{F}=896,614$; $\mathrm{p}$ $=0.00)$. at 70 Gy irradiation doses had no significant effect on the age of mosquitoes but there was a difference in the percentage of deaths [24]. Irradiated male mosquitoes must be able to survive, at least one day after release and compete with non-irradiated male mosquitoes to mate females in nature. Fecundity was one of the parameters that is not significantly affected by the control of the results of this study. Irradiation dose $60 ; 65 ; 70 ; 75 ; 80 \mathrm{~Gy}$ does not reduce the level of fecundity of female mosquitoes mated with irradiated male mosquitoes, only at a dose of $80 \mathrm{~Gy}$ with the smallest fecundity. The results of the same study were reported by Helinski in An.arabiensis, the fecundity of female mated with irradiated male at doses of 0-100 Gy showed no difference [6]. A study on An. pharoensis showed a significant increase in fecundity at $10 \mathrm{~Gy}$ irradiation doses, but not at irradiation doses of 15 and $20 \mathrm{~Gy}$, and there was a very significant decrease at 70 Gy doses [25]. Causes of reduced fecundity include the inability to lay eggs (infecundity), the inability of male mosquitoes to produce sperm (aspermia), or nonfunctional sperm and the inability to mate [26][19]. Mustofa reports that gamma irradiation greatly affects the testes, such as (i) rupture, necrosis, degeneration and small vacuole (ii) abnormal distribution of the developmental stages of spermatogonia and spermatocytes which cause a decrease in the level of spermatogenesis; and (iii) sperm deformity that inhibits sperm movement and fertility causing a decrease in the reproductive potential of $C x$. pipien [27]. In this study only male mosquitoes were subjected to irradiation, so the effect on fecundity had no effect compared to controls. This is especially seen in lower irradiation doses, although higher irradiation doses can affect the ability of male mosquitoes to produce sperm or their mating ability, this effect does not decrease in subsequent generations of F1, F2 and F3 [28].

Table 3 Fertility, fecundity and hatchability Culex quinquefasciatus in various doses of irradiation

\begin{tabular}{|c|c|c|c|}
\hline Doses & Fertility (\%) & Fecundity $(\%)$ & Hatchability (\%) \\
\hline Control & $40,00 \pm 2,16^{\mathrm{a}}$ & $111,8 \pm 10,2(95,5-128,1)^{\mathrm{a}}$ & $96,14 \pm 5,4(85,6-102,7)^{\mathrm{b}}$ \\
\hline $\mathbf{6 0} \mathbf{~ G y}$ & $22,00 \pm 1,92^{\mathrm{a}}$ & $109,3 \pm 26,5(67,5-151,4)^{\mathrm{a}}$ & $4,8 \pm 1,5(2,4-7,3)^{\mathrm{a}}$ \\
\hline $\mathbf{6 5} \mathbf{~ G y}$ & $28,00 \pm 4,00^{\mathrm{a}}$ & $117,7 \pm 9,4(102,8-132,6)^{\mathrm{a}}$ & $2,9 \pm 2,2(0,5-6,4)^{\mathrm{a}}$ \\
\hline $\mathbf{7 0} \mathbf{~ G y}$ & $43,00 \pm 3,59^{\mathrm{a}}$ & $120,7 \pm 11,1(103,1-38,4)^{\mathrm{a}}$ & $1,8 \pm 0,6(1,0-2,6)^{\mathrm{a}}$ \\
\hline $\mathbf{7 5} \mathbf{~ G y}$ & $39,00 \pm 1,89^{\mathrm{a}}$ & $109,4 \pm 11,3(91,5-127,3)^{\mathrm{a}}$ & $1,7 \pm 0,8(0,4-3,1)^{\mathrm{a}}$ \\
\hline $\mathbf{8 0} \mathbf{~ G y}$ & $31,00 \pm 2,06^{\mathrm{a}}$ & $96,4 \pm 27,5(52,7-140,2)^{\mathrm{a}}$ & $1,3 \pm 0,6(0,4-2,4)^{\mathrm{a}}$ \\
\hline
\end{tabular}

The different superscripts in the same columns show significant difference $(\mathrm{p}<0.05)$ in ANOVA Duncan's post hoc test 
while non-hatched eggs are marked by open operculum referring to the procedure described by Zheng [15].

The number of eggs produced by female mosquitoes mating with irradiated male mosquitoes with variations dosage, did not different significantly with respect to control (Table 4). The ability of mosquitoes to lay eggs is related to the structure and function of the reproductive organs. Mosquitoes with healthy reproductive organs and can carry out their functions normally, tend to be more successful in oviposition than the abnormal ones. Mosquitoes that do not lay eggs possibly because of the failure of mosquitoes to produce eggs in the ovary or oviposition. Both of these factors are related to biological aspects, especially those related to abnormalities in bodily functions caused by genetic factors [29].

The results of Sasmita and Ernawan's research on $A e$. aegypti and An. maculatus reported no difference in the average number of eggs per female mosquito at the dose $60 \mathrm{~Gy}$ with control [18][30]. The number of eggs produced by female mosquitoes is influenced by the amount of blood sucked, biological factors and ecological factors 29]. According to Clements to produce an average of $85.5 \mathrm{eggs}$ a mosquito requires an amount of $3-5 \mathrm{mg}$ of blood, otherwise eggs cannot be produced if the amount of blood that is sucked is less than $0.5 \mathrm{mg}$ [31]. Mosquito body size is a biological factor, which influences the size of the mosquito's abdomen and ovaries. Sizewise, a larger ovary as a place for egg production, has a bigger capacity and egg production will also increase. Large mosquitoes tend to have a large abdominal size and the more blood that is sucked, the more eggs tend to be produced [32]. a microscope at $4 \mathrm{x}$ magnification (Figure 2). Hatched eggs are marked by the opening of the operculum in the egg,

Table 4 Hatchability and sterility of Culex quinquefasciatus the result of mating with sterile male mosquitoes

\begin{tabular}{|c|c|c|c|c|c|c|}
\hline Doses (Gy) & $\mathbf{N}$ & Replicate & Eggs & Hatch & Hatchability (\%) & Sterility (\%) \\
\hline 0 (Control) & 25 & 4 & $4461 \mathrm{a}$ & 4305 & 96.14 & $3.82 \pm 2.16 \mathrm{a}$ \\
\hline 60 & 25 & 4 & $2266 \mathrm{a}$ & 110 & 4.81 & $95.19 \pm 1.53 \mathrm{~b}$ \\
\hline 65 & 25 & 4 & $3328 \mathrm{a}$ & 127 & 2.93 & $97.07 \pm 2.21 \mathrm{bc}$ \\
\hline 70 & 25 & 4 & $5160 \mathrm{a}$ & 90 & 1.81 & $98.19 \pm 0.49 \mathrm{c}$ \\
\hline 75 & 25 & 4 & $4307 \mathrm{a}$ & 68 & 1.75 & $98.25 \pm 0.86 \mathrm{c}$ \\
\hline 80 & 25 & 4 & $2939 \mathrm{a}$ & 42 & 1.38 & $98.62 \pm 0.60 \mathrm{c}$ \\
\hline
\end{tabular}

The different superscripts in the same columns show significant difference $(p<0.05)$ in ANOVA Duncan's post hoc test 


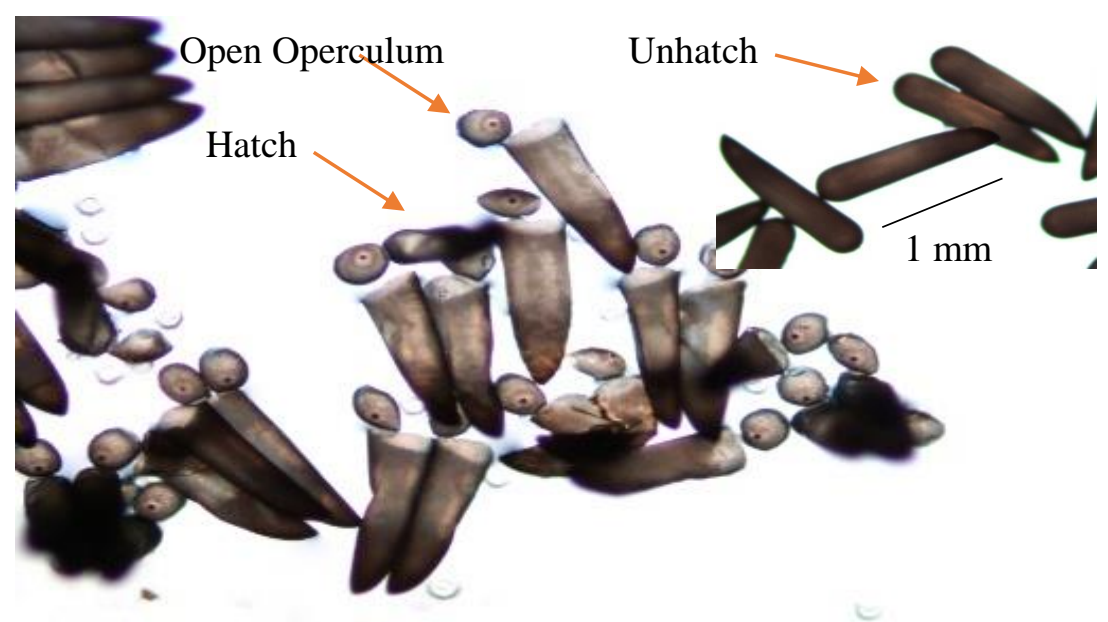

Figure 2 Eggs of Culex quinquefasciatus

Eggs produced by female mosquitoes $C x$. quinquefasciatus show that the insemination process continues but the embryo that is formed cannot survive, due to the dominant lethal mutation carried by the irradiated male mosquito sperm cells. Dominant lethal mutations do not inhibit the formation process of male and female gametes, and zygotes that occur are also not inhibited but the embryo will die [10]. Dominant lethal mutations can be seen from the hatchability of eggs which decrease with the increasing of gamma irradiation given (Table 4).

Sterility in mosquito control by the SIT method is often considered to provide $100 \%$ sterility in the target insect, so that the gamma irradiation dose is directed to reach $100 \%$ sterility. However, as research progresses it is known that too high a dose of irradiation can cause somatic cell damage thereby reducing the insect's fitness. Sterility can be interpreted as a structural or functional inability to reproduce, a total inability due to a state of reproduction; and partial or total failure in producing gametes and functional zygotes [33]. Several factors that cause sterility in male mosquitoes include lethal dominant mutations, aspermia, inactivation of sperm, inability to mate due to somatic cell damage and so on [10].

The main factor of sterility in this study is due to the dominant lethal mutation, this is indicated by the formation of eggs with unhatched embryos and the level of sterility decreases with increasing irradiation doses. Robinson describes the occurrence of dominant lethal mutations in cells [33]. As a result of gamma irradiation, chromosomes in cells become broken. If the broken chromosome is a sperm cell chromosome, the condition will occur until the sperm fertilizes the egg. Chromosomes that are broken cause effects on embryonic development. At the beginning of prophase the broken chromosome undergoes non-irradiated replication/cleavage, but during the metaphase process the chromosome fracture can combine to form a dicentric chromosome and an ascentric fragments. The ascentric fragment will disappear, while dicentric chromosome will form a bridge in the anaphase process that can trigger other chromosome breaks. The whole process repeatedly will cause accumulation and imbalance and disruption of sapling genetic information. The accumulation of genetic damage can ultimately lead to the death of zygotes and embryos, so that no offspring are produced.

In this study, gamma irradiation at a dose of $60-80 \mathrm{~Gy}$ significantly affected the sterility of male Cx.quinquefasciatus mosquitoes. The same results were shown in previous studies which stated that sterility was directly proportional to the dose of gamma irradiation. The higher the dose of irradiation, the sterility also increases $[4,17,18,20,28]$. Hosada study reported that radiation at Culex pipiens moletus (F) doses of $100 \mathrm{~Gy}$ and $120 \mathrm{~Gy}$ respectively caused egg sterility of $99.1 \%$ and $99.9 \%$, while the radiation against Ae. aegypti at doses of $65 \mathrm{~Gy}$ and 70 Gy respectively caused egg sterility of $98 \%$ and $100 \%$ [34].

Evaluate the minimum dose to sterilize mosquitoes Cx.quinquefasciatus produces higher doses than previous studies. The determine dose of gamma irradiation to spay $100 \%$ adult male mosquitoes Cx.quinquefasciatus is $70 \mathrm{~Gy}$ [5]. But in this study, a dose of $80 \mathrm{~Gy}$ did not make $100 \%$ sterile male mosquitoes $(98.62 \pm 0.60)$. Therefore, the range of existing $100 \%$ infertile dose needs to be made to 60-80 Gy. According to Helsinki 2009 sterile doses in Anopheles mosquitoes can be reached at doses of 100-120 Gy but only produce sterility levels above $98 \%$, meaning, sterile doses are not standard doses, sterile doses can change by being influenced by many factors, one of which is maturity sexual mosquito [17]. Control of mosquito populations can be achieved if sterile males released have a sterility value of $100 \%$, but it is necessary to take into account the possibility that suppression of mosquito populations in the release area can be achieved by 
pharate adults. J Ecobiotechnol. 2(4) (2010) 6-10, http://journal-ecobiotechnology.com/

but have good mating competitiveness.

\section{CONCLUSION}

Gamma irradiation at a dose of 60-80 Gy has no significant effect on the survival of the test mosquito (longevity,emergency rate and fecundity). However, it affects of the sterility and hatchability. A dose of $60 \mathrm{~Gy}$ is the minimum dose and $80 \mathrm{~Gy}$ is the maximum dose that can be used to sterilize and can inhibit egg development, so it is recommended for dosages of SIT application in the field. The effects of gamma irradiation with the same parameters need to be done continuously in the next generation, it is very important to know the effects of irradiation in the generation that is passed down.

\section{ACKNOWLEDGMENT}

Authors thank for head of Research and Development of Banjarnegara-Sourced Disease Control Health. This study was supported by Health Research and Development Agency. We also thank support from the entomology Laboratory Research and Development of Banjarnegara and PAIR BATAN Jakarta as well as for those who helped during the author conduct his research in the laboratory observation.

\section{REFERENCES}

[1] A.A. Arsin, Epidemiologi Filariasis di Indonesia Penerbit Masagena Press 2016, pp. 110

[2] R. Ramadhani, Suyoko, S. Sumarni, Culex quinquefasciatus sebagai vektor utama filariasis limfatik yang disebabkan Wuchereria bancrofti di Kelurahan Pabean Kota Pekalongan. JEK, 9(3) (2010) 1303-1310

[3] A. Parker, K. Mehta, Sterile Insect Technique: A model for dose optimization for improved sterile insect quality, Florida Entomologist. 90(1) (2007)

[4] R. Setiyaningsih, Widiarti, H. Heriyanto, Pengaruh Radiasi Sinar Gamma Co-60 Terhadap Sterilitas dan Perkembangan Embrio Culex quinquefasciatus J Med Litbangkes, 2015, 25(1): $51-58$

[5] K. Yadav, S. Dhiman, I. Baruah, L. Singh, Efffect of Gamma Radiation on survival and fertility of male Anopheles stephensi Liston, iradiated as
[6] A. Bakri, K.Mehta, D.R. Lance, Sterilizing insects with ionizing radiation. In Dyck, V. A. and Robinson, A. S. (Eds.) Sterile Insect Technique The Netherlands: Springer, 2005, pp. 233-268.

[7] M.E.H. Helinski, A.G. Parker, B.G.J. Knols, Mating competitiveness of male Anopheles arabiensis mosquitoes irradiated with a semi-or fullysterilizing dose in small and large laboratory cages J Med Entomol. 45(1) (2006) 698-705

[8] E.F. Knipling, Possibilities of Insect Control or Eradication Through the Use of Sexuality Sterile. J.Econ. Entomol, 48 (1995) 459-462

[9] H. Boesri, Prospek Penggunaan Chemosterilant sebagai Pengendali Serangga Kesehatan, JPST, 7(2) (2006) 103-118

[10] S. Sutrisno, Prinsip Dasar Penerapan Teknik Serangga Mandul untuk Pengendalian Hama pada Kawasan yang luas. Jurnal Ilmiah Aplikasi Isotop dan Iradiasi, 2(2) (2006) 35-47

[11] Rodriguez. Effects on the productivity of irradiated male population of Aedes aegypti (Diptera: Culicidae) J. Med. Entomol. 14 (4) (1997) 493-494

[12] M.E.H. Helinski, A.G. Parker, B.G.J. Knols, Sperm quantity and size polymorphism in unirradiate male of the malaria mosquito Anopheles arabiensis Patton, J Acta Tropica, 109 (2008): 64$69 . \quad$ DOI: https://doi.org/ 10.1016/j.actatropica.2008.10.002

[13] R. Bellini, F. Balestrino, A. Medici, G. Gentile , R. Veronesi, M. Carrieri, Mating Competitiveness of Aedes albopictus Radio-Sterilized Males in Large Enclosures Exposed to Natural Conditions, J Med Entomol. 50(1) (2013) 94-102. DOI: https://doi.org/ 10.1603/me11058

[14] D. Zhang, R.S. Lees,Z. Xi, K. Bourtzis, J.R.L. Gilles, Combining the Sterile Insect Technique with the Incompatible Insect Technique: IIIRobust Mating Competitiveness of Irradiated Triple Wolbachia-Infected Aedes albopictus Males under Semi-Field Conditions, J PloS ONE, 10(4) (2016) 1-13. DOI:https://doi.org 10.1371/journal.pone.0151864 
[23] A.H. Amin, A.H. Kansouh, A.M. Wakid, M.A.S. Aly, AA Shoman, Biological Effect of Gamma Radiation on The Mosquito, Culex Pipiens L, pp. 237-251 chikungunya vectors Aedes aegypti and Aedes albopictus (Diptera: Culicidae)-II-Egg storage and hatching, J Parasites Vectors, 10 (2015) 1-7. DOI:htpps://doi.org/ 10.1186/s13071-015-0951-X

[16] A.A. Abdel-Malek, A.O. Tantawy, A.M. Wakid, Studies on the eradication of Anopheles pharoensis Theobald by the Sterile-Male technique using cobalt-60. III. Determination of the Sterile Dose and its biological effects on different characters related to Fitness components. J Econ Entomol. 60 (1967)

[17] M.E.H. Helinski, A.G. Parker, B.G.J. Knols, Sperm quantity and size variation in un-irradiated and irradiated males of the malaria mosquito Anopheles arabiensis Patton, J Acta Tropica, 109 (2009) 64-69

[18] H.I. Sasmita, B. Ernawan, Kualitas Nyamuk Jantan Mandul Aedes aegypti L. Hasil Iradiasi Gamma: Efek Iradiasi Pada Fase pupae dan Dewasa. Jurnal Ilmiah Aplikasi Isotop dan Radiasi, 10(2) (2014) 149-158

[19] D.R. Lance, D.O. McInnis, Biological basis of the sterile insect technique. In Dyck, VA and Robinson AS (Eds.) Sterile Insect Technique Principles and Practice in Area-Wide Integrated Pest Management. The Netherlands: Springer, 2005, pp. 69-94

[20] V.P. Sharma, R.K. Razdan, M.A. Ansari, Anopheles stephensi: Effect of gamma-radiation and chemosterilants on the fertility and fitness of males for sterile male releases, J. Econ Entomol, 71 (1978) 449-452

[21] C.F. Oliva, M.J. Maier, J. Gilles, M. Jacquet, G. Lemperiere, S. Quilici, M.J.B. Vreysen. F. Schooneman, D.D. Chadee, S. Boyer, Effects of irradiation, presence of females, and sugar supply on the longevity of sterile males Aedes albopictus (Skuse) under semi-field conditions on Reunion Island. J Acta Tropica, 125(3) (2013) 287-293

[22] C.O. Calkins, A.G. Parker, Sterile insect quality In: V.A. Dyck, A.S. Robinson (Eds.), Sterile Insect Technique Principles and Practice in AreaWide Integrated Pest Management. The Netherlands: Springer, 2005, pp. 269-296 
[32] B.J. Herms, Medical Entomology $4^{\text {th }}$ ed. New York (US): The Mc Millan Co, 1950

[33] A.S. Robinson, Genetic basis of the sterile insect technique. In V.A. Dyck, A.S. Robinson (Eds.), Sterile Insect Technique Principles and Practice in Area-Wide Integrated Pest Management, The Netherlands: Springer, 2005, pp. 95-114

[34] H. Hosada, The Effect of Gamma Irradiation on Fertility and mating Competitiveness of the Mosquito, Culex pipiens moletus F (Diptera: Culicidae). Applied Entomology and Zoology, 1972 